\title{
Continuous Distributions of Ventilation-Perfusion
}

\section{Ratios in Normal Subjects Breathing Air and $100 \% \mathrm{O}_{2}$}

\author{
Peter D. Wagner, Raymond B. Laravuso, Richard R. UhL, and \\ JOHN B. WEST \\ From the Departments of Medicine and Anesthesia, School of Medicine, \\ University of California San Diego, La Jolla, California 92037
}

\begin{abstract}
A B S T R A C T A new method has been developed for measuring virtually continuous distributions of ventilation-perfusion ratios $\left(\dot{\mathrm{V}}_{\mathrm{A}} / \dot{\mathrm{Q}}\right)$ based on the steadystate elimination of six gases of different solubilities. The method is applied here to 12 normal subjects, aged 21-60. In nine, the distributions were compared breathing air and $100 \%$ oxygen, while in the remaining three, effects of changes in posture were examined. In four young semirecumbent subjects (ages 21-24) the distributions of blood flow and ventilation with respect to $\dot{V}_{\mathbf{A}} / \dot{Q}$ were virtually log-normal with little dispersion (mean log standard deviations 0.43 and 0.35 , respectively). The $95.5 \%$ range of both blood flow and ventilation was from $\dot{V}_{A} / Q$ ratios of $0.3-2.1$, and there was no intrapulmonary shunt $\left(\dot{\mathrm{V}}_{\mathrm{A}} / \dot{\mathrm{Q}}\right.$ of 0$)$. On breathing oxygen, a shunt developed in three of these subjects, the mean value being $0.5 \%$ of the cardiac output. The five older subjects (ages 39-60) had broader distributions (mean log standard deviations, 0.76 and 0.44 ) containing areas with $\dot{V}_{A} / Q$ ratios in the range $0.01-0.1$ in three subjects. As for the young subjects, there was no shunt breathing air, but all five developed a shunt breathing oxygen (mean value $3.2 \%$ ), and in one the value was $10.7 \%$. Postural changes were generally those expected from the known effects of gravity, with more ventilation to high $V_{A} / Q$ areas when the subjects were erect than supine. Measurements of the shunt while breathing oxygen, the Bohr $\mathrm{CO}_{2}$ dead space, and the alveolar-arterial oxygen difference were all consistent with the observed distributions. Since the method involves only a short infusion of dissolved inert gases, sampling of arterial blood and expired gas, and measurement of cardiac output and minute venti-
\end{abstract}

This work was presented in part at the national meeting of the Federation of American Societies for Experimental Biology, April 1973.

Received for publication 30 November 1973 and in revised form 18 Febrary 1974. lation, we conclude that it is well suited to the investigation of pulmonary gas exchange in man.

\section{INTRODUCTION}

It has been known for many years that the distribution of ventilation-perfusion ratios $\left(\dot{\mathbf{V}}_{\mathbf{A}} / \dot{\mathbf{Q}}\right)$ is uneven in the lungs of normal subjects. The work of Martin, Cline, and Marshall (1) in 1953 and of Mattson and Carlens (2) in 1955 demonstrated interlobar differences in $\mathrm{O}_{2}$ and $\mathrm{CO}_{2}$ concentrations best explained by regional differences in ventilation and blood flow. Measurements using radioactive gases (3) demonstrated uneveness of both ventilation and blood flow topographically from apex to base, and indicated a range of $\dot{V}_{A} / \dot{Q}$ of from approximately 3 at the apex to 0.6 at the base in 16 seated normal volunteers. Since external counting methods cannot cover all regions of the lungs, and in addition represent averages in those areas within the counting fields, this range of $\dot{\mathrm{V}}_{\mathrm{A}} / \dot{Q}$ is likely to be an underestimate of the actual degree of ventilationperfusion inequality. Thus radioactive gas measurements do not permit accurate definition of the shape, position, or dispersion of the distribution of $\dot{V}_{\mathbf{A}} / \dot{Q}$ in normal subjects, and certainly in lung disease where the inequality is more marked, external counting gives little information on the distribution.

Several workers, notably Riley, Cournand, and Donald (4,5) and Briscoe (6) have developed methods for quantifying the degree of $\dot{V}_{A} / \dot{Q}$ inequality in terms of two or three parallel $\dot{V}_{\mathbf{A}} / \dot{Q}$ compartments. Riley and Cournand, for example, divided the lungs into three units on the basis of the arterial and expired pressures of $\mathrm{O}_{2}$ and $\mathrm{CO}_{2}$. One unit was unventilated, one unperfused, and the third was the ideal compartment. The amount of blood flow in the unventilated unit was termed venous admixture and the ventilation in the unperfused unit was called physiological dead space, 
measurements widely used in clinical practice. Although such analyses can always account for the abnormalities in gas exchange in individual patients, they give little insight into the characteristics of the $\dot{V}_{A} / \dot{Q}$ distributions that actually exist. Not only do factors other than the shape, position, and dispersion of the distribution affect these parameters, but more than one $\dot{\mathrm{V}}_{\mathrm{A}} / \dot{\mathrm{Q}}$ distribution may be found consistent with the measured venous admixture and physiological dead space.

A third approach, based on the pulmonary exchange of poorly soluble inert gases (7), also suggested the presence of ventilation-perfusion inequality in normal man, but again, although distributions compatible with the measurements could be found, there was insufficient information to define the characteristics of the actual distributions.

Lenfant and Okubo $(8,9)$ reported the first continuous distributions of $\dot{V}_{\mathbf{A}} / Q$ using a method based on the continuously measured arterial $\mathrm{P}_{\mathrm{O}_{2}}$ and expired nitrogen concentration during a nitrogen washout. Their results depended on a lack of change of the distribution as the inspired $\mathrm{O}_{2}$ concentration was raised, an assumption that Lenfant himself (10) pointed out may be unjustified. A further assumption was that none of the alveolar-arterial $\mathrm{P}_{\mathrm{O}_{2}}$ difference at any inspired $\mathrm{O}_{2}$ concentration was due to alveolar-capillary diffusion impairment. While this is reasonable in normal subjects, it may not be so in some patients with lung disease. Finally, the mathematical basis of the method has been criticized (11) as being insensitive.

We recently described a method (12) for measuring the distribution of $\dot{V}_{A} / \dot{Q}$ based on the simultaneous steady-state pulmonary elimination of six inert gases of widely different solubilities. In this procedure, we made use of the principles governing inert gas exchange in the lung described by Farhi (13) and applied by Klocke and Farhi (14) and Yokoyama and Farhi (15). The method is suitable for experimental animal studies and also for studies both of normal subjects and of patients with acute or chronic lung disease. The position, shape, and dispersion of the distributions of both ventilation and blood flow are derived, and in addition the true intrapulmonary shunt and amount of ventilation to unperfused areas are determined. It is therefore possible to discriminate directly between shunting and ventilation-perfusion inequality as causes for hypoxemia in any individual case, without the need for breathing $100 \% \mathrm{O}_{2}$, which, as pointed out, may alter the distribution and thereby give rise to error.

This paper reports the application of this method in 12 normal human volunteers ranging in age from 21 to 60 . In nine of the subjects, measurements were made in the semirecumbent position both during air and
$100 \% \mathrm{O}_{2}$ breathing, while in the remaining three, measurements were made in the supine and erect positions.

\section{METHODS}

General outline. Indwelling catheters were placed in the radial artery and a peripheral arm vein, and a narrow catheter was introduced via an antecubital vein to the region of the shoulder. The six gases, sulfur hexafluoride $\left(\mathrm{SF}_{6}\right)$, ethane, cyclopropane, halothane, diethyl ether, and acetone, are dissolved in a suitable solvent, such as $5 \%$ dextrose or normal saline, and the resulting mixture is infused into the peripheral venous catheter at $2-5 \mathrm{ml} / \mathrm{min}$ for some $20 \mathrm{~min}$ to reach a steady state of gas exchange within the lungs. Samples of mixed arterial blood and mixed expired gas are collected at this time, and minute ventilation and cardiac output (dye dilution) are measured. The concentrations of the six gases in each sample are determined by gas chromatography (16) and the solubility of each gas in blood is also measured. By using the Fick principle, the mixed venous concentration of each gas is then calculated, and two graphs are drawn. The first is the plot of the ratio of arterial to mixed venous concentrations against solubility (retention-solubility curve) and the second is the plot of the ratio of mixed expired to mixed venous concentrations against solubility (excretion-solubility curve). Then, by techniques of numerical analysis described elsewhere (12), the retention-solubility curve is transformed into a virtually continuous plot of blood flow against $V_{A} / \dot{Q}$, and the excretion-solubility curve is similarly transformed into the plot of ventilation against $\dot{\mathrm{V}}_{\mathrm{A}} / \dot{\mathrm{Q}}$.

Selection of subjects. Seven male volunteer college students, aged 21-24, and five male volunteers, aged 39-60, were chosen for these studies. The procedures and their risks were carefully explained to each subject and informed consent was obtained before the study.

The following criteria for selection were used: (a) A history of never having smoked tobacco. (b) A negative history of cardiopulmonary disease, except for the usual viral infections. (c) No known disease in any other organ system. (d) A history of no general anesthesia with halothane in the last year. The reason for this criterion was to minimize the very slight risk of halothane liver damage. (e) Normal physical examination. ( $f$ ) Normal chest X-ray. One subject, E.L., showed a minimal old apical scar, never associated with symptoms of tuberculosis or functional impairment, and this was not deemed sufficient ground for exclusion from the study. $(g)$ Normal standard pulmonary function tests, including vital capacity, total lung capacity, functional residual capacity (helium dilution), residual volume, closing volume, and a forced expiratory maneuver. (h) Normal electrocardigram, hemoglobin, and hematocrit. Anthropometric data appear in Table I.

It is of interest that of 10 applicants in the 39-60 yr age group, five were found on physical examination or laboratory test to have significant abnormalities unknown to them. Each was rejected for this study but referred for further evaluation.

Preparation of subjects. The subjects were studied in the morning in the fasting state. With local anesthesia $(1 \%$ Xylocaine [Astra Pharmaceutical Products, Inc., Worcester, Mass.] without adrenalin) and sterile technique, 20-gauge Medicut cannulas (A. S. Aloe Co., St. Louis, Mo.) were inserted into the radial artery of the nondominant hand and into the contralateral arm peripheral vein. In each subject, adequate ulnar arterial supply was first established to guard against the risk of digital ischemia from the radial artery cannula. A catheter (Bardic radio-opaque inside needle catheter, C. R. Bard, Inc., Murray Hill, N. J.) was introduced 
TABLE I

Anthropometric Data

\begin{tabular}{|c|c|c|c|c|c|c|c|c|c|c|c|c|}
\hline \multirow[b]{2}{*}{ Subject } & \multicolumn{4}{|c|}{ Group I } & \multicolumn{5}{|c|}{ Group II } & \multicolumn{3}{|c|}{ Group III } \\
\hline & $\begin{array}{c}1 \\
\text { R. D. }\end{array}$ & $\stackrel{2}{\text { M. H. }}$ & $\stackrel{3}{\text { M. S. }}$ & $\begin{array}{c}4 \\
\text { P. B. }\end{array}$ & $\begin{array}{c}5 \\
\text { w. c. }\end{array}$ & $\begin{array}{c}6 \\
\text { A. } \mathrm{H} .\end{array}$ & $\stackrel{7}{\text { E. L. }}$ & $\begin{array}{c}8 \\
\text { D. H. }\end{array}$ & $\stackrel{9}{\text { F. M. }}$ & $\begin{array}{c}10 \\
\text { G. S. }\end{array}$ & $\begin{array}{c}11 \\
\text { J. S. }\end{array}$ & $\begin{array}{c}12 \\
\text { B. T. }\end{array}$ \\
\hline Age, $y r$ & 24 & 21 & 22 & 21 & 44 & 55 & 45 & 60 & 39 & 21 & 22 & 21 \\
\hline Vital capacity, liters & 5.7 & 5.2 & 5.5 & 5.2 & 6.2 & 4.1 & 4.6 & 4.3 & 5.4 & 6.1 & 5.7 & 6.0 \\
\hline Total lung capacity, liters & 7.1 & 7.1 & 7.7 & 6.5 & 8.2 & 4.9 & 6.5 & 5.6 & 7.2 & 7.8 & 7.8 & 7.8 \\
\hline \multicolumn{13}{|l|}{ Functional } \\
\hline residual capacity, liters & 3.9 & 4.1 & 4.7 & 2.9 & 4.0 & 2.2 & 2.8 & 1.9 & 2.6 & 3.8 & 4.2 & 3.6 \\
\hline Residual volume, liters & 1.4 & 1.9 & 2.2 & 1.3 & 2.0 & 0.8 & 1.9 & 1.3 & 1.8 & 1.7 & 2.1 & 1.8 \\
\hline $\mathrm{RV} / \mathrm{TLC}, \%$ & 20 & 26 & 28 & 20 & 24 & 16 & 29 & 23 & 25 & 22 & 27 & 23 \\
\hline \multicolumn{13}{|l|}{ Closing } \\
\hline capacity (sitting), \% & 23 & 30 & 30 & 28 & 33 & 29 & 38 & 33 & 27 & 24 & 30 & 28 \\
\hline $\mathrm{FEV}_{1}, \%$ & 90 & 87 & 80 & 77 & 73 & 78 & 81 & 77 & 79 & 81 & 79 & 80 \\
\hline Height, $\mathrm{cm}$ & 175 & 183 & 193 & 183 & 178 & 166 & 170 & 180 & 178 & 194 & 193 & 192 \\
\hline Weight, $k g$ & 80 & 79 & 91 & 68 & 89 & 71 & 70 & 82 & 84 & 82 & 80 & 72 \\
\hline
\end{tabular}

via a suitable antecubital vein to the region of the shoulder. This line served only as the site for injection of dye for cardiac output measurements. All three lines were placed percutaneously, and, as a precaution, under continuous electrocardiographic monitoring.

The subject was then placed in the body position chosen for the study and connected to the appropriate inspired gas mixture. For all measurements, the same mouthpiece and valve box (Collins pulmonary function laboratory breathing valve P-316, Warren E. Collins, Inc., Braintree, Mass.) was used. While breathing air, subjects were connected to the mouthpiece 5-10 min before the initial sampling, whereas during $100 \% \mathrm{O}_{2}$ breathing, they were connected by necessity for the duration of the study.

Experimental groups. Four of the seven young subjects formed group I and all of the five older subjects formed group II. These were studied both while breathing room air and $100 \%$ oxygen. Six (three young and three older) were studied first breathing room air and then oxygen, while in the remainder, the measurements were made in the reverse order. In all cases, the subjects were semirecumbent at an angle of between 30 and 40 degrees to the horizontal throughout the measurements. In any one subject, body position remained unaltered for the duration of the study.

The three remaining young subjects formed group III. Each was studied breathing room air only, but in the supine and erect (sitting) positions. In two, the measurements were made first erect and then supine, while in the third subject, the reverse order was used.

Method of solution of the six test gases. Gas from a tank containing approximately $20 \% \mathrm{SF}_{6}, 20 \%$ cyclopropane, and $60 \%$ ethane was passed through a $0.22-\mu \mathrm{m}$ Millipore filter (Swinnex-25, Millipore Corp., Bedford, Mass.) and then bubbled via sterile tubing into a $500-\mathrm{ml}$ bottle of sterile $5 \%$ dextrose (or saline) so as to replace the air in the bottle with the gas mixture. The tank was turned off, and the bottle shaken vigorously for several seconds. The gas in the bottle was then replaced by further bubbling of the tank mixture, and the process repeated twice more.

With the above gas mixture bubbling very slowly into the bottle, $1 \mathrm{ml}$ of liquid diethyl ether, analytical reagent grade, was next injected directly into the bottle with a sterile needle and syringe. This was followed by $5 \mathrm{ml}$ of similar-grade acetone. No shaking of the bottle was needed, since both substances, being very water-soluble, disperse rapidly. Shaking at this stage could have resulted in loss of the poorly soluble gases already in solution, since due to the presence of ether and acetone, the gas above the dextrose must have reduced partial pressures of the poorly soluble gases.

Five of the six gases were now in solution, and at this stage the dextrose was transferred into sterile, pyrogen-free, ungreased 200-ml glass syringes (Becton-Dickinson \& Co., Rutherford, N. J.). We found these the most convenient form of reservoir, since their volume was readily reduced as the infusion took place without exposure of the solution of gases to air. This transfer was accomplished anaerobically and with sterile technique.

The final gas, halothane, was added directly to the syringes, rather than together with ether and acetone, because it is relatively insoluble in water and would require considerable agitation for even dispersion. As pointed out, such agitation is undesirable. $1 \mathrm{ml}$ of liquid halothane was injected into each $200-\mathrm{ml}$ syringe of dextrose, after which the syringe, free of all bubbles, was inverted several times to dissolve the halothane. Some, however, remained undissolved, but since halothane is much denser than water, it lay in the dependent part of the syringe and therefore could not be infused because the syringe was kept horizontal at all times. The solution was now ready for infusion into the subject.

Several points may be made concerning the technique for preparing the infusate. The concentrations of the gases in the tank need not be known accurately since the distribution of $\dot{V}_{A} / \dot{Q}$ is obtained only from measurements of concentrations in arterial blood and expired gas; the concentrations of the gases in the infusate do not enter the calculations. Equilibration of the gases with dextrose need not be complete for the same reason. The relative proportion of each gas in the infusate has been selected so as to result in approximately uniform concentrations in the arterial blood and so increase the accuracy of measurement. All major receptacles of the infusate (and expired gas and arterial blood samples) must be of grease-free glass or metal, since some of the gases are soluble in plastic and grease and would therefore be partly lost from the solution. 
The infusate was examined on several occasions for both sterility and freedom from pyrogens. Neither organisms nor pyrogens have ever been detected.

When infusing at the usual rate of $5 \mathrm{ml} / \mathrm{min}$, systemic arterial concentrations of each gas never reach more than one part per 100,000 and are usually an order of magnitude less than that. Their presence was not usually noticed by the subjects.

Infusion of the solution of the six gases. With the subject in the desired position and breathing the appropriate inspired gas mixture, the infusion was begun after assurance of steadystate conditions, criteria of which were a stable pulse rate, blood pressure, and respiratory frequency. Closer to the time of measurements, additional information regarding the steady state was collected. This included measurements of cardiac output, minute ventilation, and both end-tidal and mixed expired $\mathrm{P}_{2}$ and $\mathrm{P}_{\mathrm{CO}_{2}}$, measured continuously by mass spectrometer.

The solution was infused into the peripheral venous cannula through a $0.22-\mu \mathrm{m}$ Millipore filter as a precaution against bacterial contamination. Both infusion and roller pumps were u sed on different occasions to introduce the material at a rate of $5 \mathrm{ml} / \mathrm{min}$. After $15 \mathrm{~min}$ of infusion, subjects not breathing $100 \% \mathrm{O}_{2}$ (and hence not on a mouthpiece) were connected to the mouthpiece and valve box. This permitted continuous measurements of minute ventilation, collection of expired gases, and monitoring of tidal fluctuation in $\mathrm{P}_{\mathrm{O}_{2}}$ and $\mathrm{P}_{\mathrm{CO}_{2}}$. After a further $5 \mathrm{~min}$ to allow for any change in breathing pattern (which was always small), and with the infusion continuing, an initial set of measurements was made (described below). 5 min later, a duplicate set of measurements was made while the infusion continued.

When both sets of data had been collected, the infusion was stopped, the mouthpiece removed, and the subject allowed to rest (in the same body position in groups I and II) for some $15 \mathrm{~min}$.

A second study was then performed, exactly as above, under a new set of physiological conditions as set out in the section of experimental groups. At least $15 \mathrm{~min}$ were allowed for each subject to reach a new steady state before the infusion was begun, so that by the time the measurements were made, the subject had been exposed to the new conditions for at least $35 \mathrm{~min}$. In the case of $100 \% \mathrm{O}_{2}$ breathing, a nitrogen washout was obtained and the level of expired nitrogen at the time of measurement was also available, confirming virtually complete denitrogenation (end-tidal $\mathrm{N}_{2}$ concentrations of less than $1 \%$ ).

Measurements. In temporal sequence, the following steps made up one set of measurements, as referred to above:

(a) A heparinized 15-ml blood sample from the radial artery, for determination of the concentrations of the six gases. The blood was withdrawn steadily over $30 \mathrm{~s}$ to damp respiratory oscillations in gas concentration. Sterile ungreased glass syringes were used.

(b) A simultaneous sample of mixed expired gas also collected in an ungreased glass syringe for measurement of the six gases. Leakage of gas from these syringes was minimized by the use of syringes with matched barrel and plunger. Simultaneous samples of blood and gas were taken because of the steady rise in concentrations of the gases during the infusion. Mixed expired gas was required rather than endtidal, because the latter is not representative of all alveoli, and this required a mixing system. Further, the mixing system had to be made of either metal or glass to avoid absorption of gases such as halothane, ether, and acetone, and heated above body temperature to avoid the loss of the water-soluble gases in condensed water vapor.
Our solution was to build a long coil of copper pipe (diameter, $1.5 \mathrm{in}$; approximate length, $30 \mathrm{ft}$ into a heated insulated box). The subject's expiratory line was connected to one end, and by the time expired gas had traveled the length of the pipe, sufficient mixing had occurred to completely eliminate tidal fluctuations in gas concentration. Thus, mixed expired gas could be sampled at the effluent end of the pipe. In order to make physiologically simultaneous collections of arterial blood and expired gas with this sytem, a delay period was required between the arterial blood sample and the mixed expired gas sample. This delay represents the finite time for travel of the expired gas through the copper pipe, and was calculated in the following way. First, the entire pipe and connections were filled with room air. Then a subject was connected to the valve box and asked to breath normally and regularly. Cumulative expired volume was measured from the time of collection, and with a mass spectrometer, the $\mathrm{P}_{\mathrm{CO}_{2}}$ at the effluent end of the system was measured continuously. For a period of time approximately equal to the volume of the collection system (about 12 liters) divided by minute ventilation, the $\mathrm{P}_{\mathrm{CO}_{2}}$ remained equal to that in room air, but then began to rise over the next three breaths until a plateau concentration was reached. By the same principle as that employed in the measurement of anatomic dead space by the Fowler single-breath method, the effective volume of the entire collection system could thus be measured. This volume was 12.5 liter, and was independent of the level of minute ventilation over the range tested, namely, 8-40 liter $/ \mathrm{min}$.

(c) A 3-ml Heparinized radial artery sample for $\mathrm{P}_{\mathrm{O}_{2}}, \mathrm{P}_{\mathrm{CO}_{2}}$, and $\mathrm{pH}$. Analysis was performed within $5 \mathrm{~min}$, with the samples kept in glass syringes on ice before measurement. Radiometer blood gas electrodes were used. The oxygen electrode was calibrated with low and high $\mathrm{O}_{2}$ mixtures containing $5 \% \mathrm{CO}_{2}$ before blood measurements were made. The blood-gas correction factor was determined by tonometering blood samples with these $\mathrm{O}_{2}$ mixtures on several occasions.

(d) Minute ventilation and respiratory frequency were measured minute-to-minute over the $4 \mathrm{~min}$ bracketing the blood sampling. Ventilation was measured with a calibrated Wright respirometer.

(e) Cardiac output was measured by dye dilution. $2 \mathrm{ml}$ of indocyanine green $(5 \mathrm{mg})$ were injected into the venous cannula placed near the shoulder, and arterial blood was sampled from the radial artery. A Gilford densitometer (Gilford Instrument Laboratories, Inc., Oberlin, Ohio) was used to measure dye concentration, and the curves were recorded on a Brush recorder (Series 200, Gould Inc., Instruments System Div., Cleveland, Ohio). Replotting of the downslopes was done by hand, and the areas of the curves planimetered. A four-point calibration of the densitometer was performed.

$(f)$ Continuous measurements of both tidal and mixed expired $\mathrm{P}_{\mathrm{O}_{2}}$ and $\mathrm{P}_{\mathrm{CO}_{2}}$ were obtained with a Perkin-Elmer respiratory mass spectrometer (Perkin-Elmer Corporation, Pomona, Calif.) whenever subjects were on the mouthpiece. In addition, tidal nitrogen concentrations were measured during oxygen breathing.

On the day of the study, hemoglobin concentration and hematocrit were measured in the hospital laboratory. In addition, plasma hemoglobin estimations were performed before and after the study. The purpose of these measurements was to monitor possible hemolytic effects of the solution of gases. Halothane in high concentration is known to hemolyze blood, but in preliminary in vitro tests, no hemolysis was found to occur at concentrations 100 times greater than those present in the subjects. Plasma hemoglobin values rose by a 


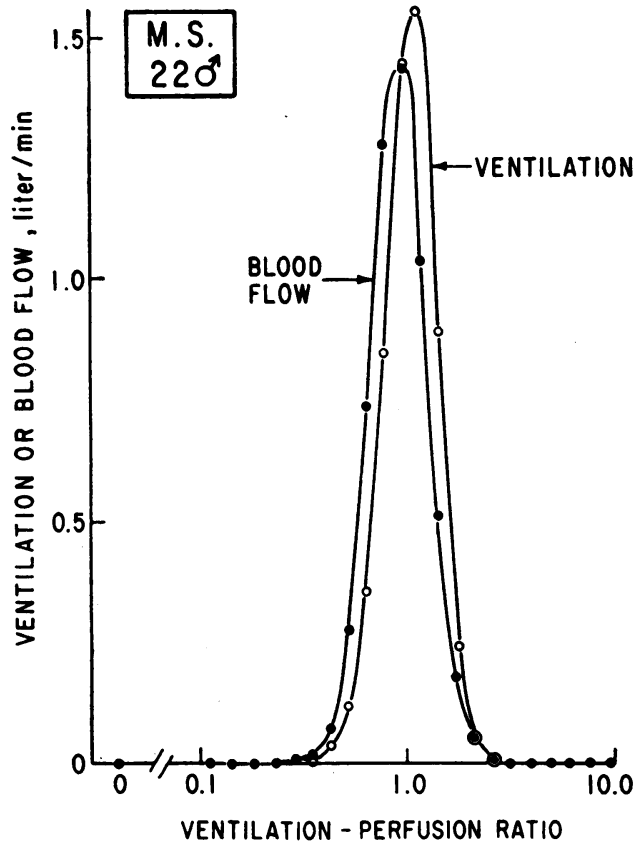

FIGURE 1 The distribution of ventilation and blood flow in a young subject, M. S., breathing room air. There is very little dispersion in either curve with no areas of high or low $\dot{\mathrm{V}}_{\mathrm{A}} / \dot{\mathrm{Q}}$. There is no shunt. Both distributions are appropriately positioned about a $\dot{\mathrm{V}}_{\mathbf{A}} / \dot{Q}$ close to 1.0 , and are symmetrical on a $\log$ scale.

mean of $5 \mathrm{mg} / 100 \mathrm{ml}$ over the course of the study, equivalent to less than $2 \mathrm{ml}$ of blood being hemolyzed. We ascribe this minor hemolysis to the reinfusion of blood withdrawn during the cardiac output determinations.

Gas chromatography. The concentrations of the six test gases in both mixed expired gas and arterial blood were determined by gas chromatography. A Beckman gas chromatograph (GC) ${ }^{1}$ model GC $72-5$ with both flame ionization detector (FID) and electron capture detector (ECD) was used (Beckman Instruments, Inc., Fullerton, Calif.). SF 6 was measured with the ECD, while the remaining five gases were detected by the FID.

Because only ratios of concentrations were needed, absolute calibration of the GC was unnecessary. Since the FID is linear over a wide range with respect to peak height, raw peak height data were sufficient for computation of the gas concentration ratios. However, the ECD is inherently alinear, so that a relative calibration curve was necessary for $\mathrm{SF}_{6}$. This was readily obtained by means of serial dilutions of the most concentrated sample of $\mathrm{SF}_{6}$.

Expired gas samples were introduced into the GC directly via a $2-\mathrm{ml}$ constant volume inlet loop. To measure the gases in arterial blood, they were first extracted into helium which was then introduced as above into the GC. The method of extraction and measurements is described elsewhere in detail (16) and is similar in principle to that originally described by Hamilton (17). It consists of equilibrating known volumes of arterial blood and helium at the temperature of the subject for a period of $40 \mathrm{~min}$. The once-equilibrated blood is then

${ }^{1}$ Abbreviations used in this paper: ECD, electron capture detector; FID, flame ionization detector; GC, gas chromatograph. re-equilibrated with a second volume of helium as before, and from the ratio of the two peak heights obtained at each equilibration, the solubility of each gas may be calculated. This enables the original blood concentration and solubility to be computed for each gas.

For the FID, the carrier gas (helium) flow rate was $50 \mathrm{ml} /$ min, and column temperature $170^{\circ} \mathrm{C}$. For the ECD, helium flow rate was $25 \mathrm{ml} / \mathrm{min}$ and temperature $80^{\circ} \mathrm{C}$. In both cases, the same column was used, namely, Poropak-T 80/100 mesh, $6 \mathrm{ft}$ long, and $\frac{1}{8}$ th in diameter (stainless steel). The column was obtained prepacked from Beckman Instruments, Inc.

Computer analysis. From the ratio of mixed expired to arterial concentrations for each gas, the solubility of each gas, and minute ventilation and cardiac output, the arterial-tovenous ratio and expired-to-venous ratio of concentrations for each gas were calculated by means of the Fick principle.

As described in the general outline, these ratios, together with the measurements of solubility, constitute all the necessary data for the determination of both the distribution of ventilation and of blood flow with respect to $\dot{V}_{A} / \dot{Q}$. These distributions are not unique in a strict mathematical sense, because they are calculated in terms of a large number (50) of compartments. However, all possible distributions that can be derived from a given set of data can be shown to be virtually indistinguishable, so that a single useful solution can be obtained. This concept is considered in detail elsewhere (12), where the principles of the numerical analysis that transform the data into the distributions are also described. The computer program for this analysis is written in Fortran and is directly executable on most large computers, including the Control Data 3600 and Burroughs 6700 digital computers. Execution time on such a computer varies between 1 and 3 min depending on the complexity of the distribution, since the iterative methods take longer to converge upon a complex shape than upon a simple one. The computer program is available from the authors.

\section{RESULTS}

\section{Distributions of $\dot{\mathrm{V}}_{\mathbf{A}} / \dot{\mathrm{Q}}$ in semirecumbent subjects breathing air}

Group 1: young subjects aged 21-24 yr. Fig. 1 shows typical distributions of ventilation and blood flow against $\dot{\mathrm{V}}_{\mathbf{A}} / \dot{Q}$ in a young normal subject (M.S.). $\dot{\mathrm{V}}_{\mathbf{A}} / \dot{Q}$ is shown on a log scale and the individual points showing blood flow and ventilation add up to the total cardiac output and ventilation, respectively. The line joining the individual points is for clarity only. Note how little dispersion there is in either curve. A useful index of the dispersion is the standard deviation of the distribution calculated with a natural log scale for the abscissa (log SD). In this case, $\log \mathrm{SD}$ was 0.32 for blood flow and 0.29 for ventilation. The values in Table II are the means of two measurements made 5 min apart.

Although an attenuated scale for $\dot{V}_{\mathbf{A}} / \dot{Q}$ is used in Fig. 1 (only the region of $\dot{V}_{A} / \dot{Q}$ from 0.1 to 10.0 is plotted) the analysis of this subject's data was performed routinely, namely, by obtaining the solution over the entire working $\dot{\mathrm{V}}_{\mathbf{A}} / \dot{Q}$ range of from 0.005 to 100.0. The reason for using this attenuation was that all the points for blood flow and ventilation outside the 
range in Fig. 1 had a value of zero. In fact, it can be seen that all the blood flow and ventilation was confined to the $\dot{V}_{\mathrm{A}} / \dot{Q}$ range, 0.3-3.0.

The positioning of the two curves is appropriate to the ratio of total alveolar ventilation ( $5.3 \mathrm{liter} / \mathrm{min})$ to cardiac output $(5.8 \mathrm{liter} / \mathrm{min})$ in this subject. The $\dot{\mathrm{V}}_{\mathrm{A}} / \dot{\mathrm{Q}}$ ratio at the mean of the blood flow distribution was 0.87 , while that at the mean of the ventilation distribution was 1.0. The ratio of total alveolar ventilation to cardiac output was 0.91 , very close to the geometric mean of 1.0 and 0.87 , namely, 0.93. Logarithmically normal distributions with similar degrees of dispersion behave so that the geometric average of the mean $\dot{\mathrm{V}}_{\mathrm{A}} / \dot{\mathrm{Q}}$ of blood flow and ventilation coincides with the ratio of total alveolar ventilation to cardiac output. As may be seen from Fig. 1, both distributions are virtually symmetrical on the logarithmic scale, making them logarithmically normal.

Another striking feature was the absence of shunt. None of the subjects in this group had any shunt while breathing air, Table II. As will be discussed later, the present method measures only intrapulmonary and intracardiac shunt, in contrast to standard methods based on $100 \%$ oxygen breathing, which also include the shunt due to bronchial and Thebesian venous admixture. Thus, in the semirecumbent young subjects, there were no perfused regions of the lung that were completely unventilated. It should be noted that the present method is very sensitive at detecting the degree of shunt. This is because of the behavior of $\mathrm{SF}_{6}$, the least soluble gas. In a normal subject, the arterial concentration of $\mathrm{SF}_{6}$ is about $0.5 \%$ of the venous level, but if a shunt of $1 \%$ developed, this value would rise to $1.5 \%$, or three times the previous level. As a result, small shunts can be detected with considerable accuracy.

The summarized results for the young subjects (group 1) breathing air are shown in Table II. The average dispersion, estimated by the mean $\log \mathrm{SD}$ for the group, was 0.43 for the blood flow distributions and 0.35 for ventilation. As a guide to the physiological effects of this degree of dispersion, it is useful to examine the ideal alveolar-arterial oxygen difference produced by log-normal distributions with similar dispersion. A $\log \mathrm{SD}$ of 0.3 is associated with an $\mathrm{O}_{2}$ difference of approximately $5 \mathrm{~mm} \mathrm{Hg}$; one of 0.4 with $9 \mathrm{~mm} \mathrm{Hg}$, and one of 0.5 with $14 \mathrm{~mm} \mathrm{Hg}$. These values are for for lungs with normal overall $\dot{V}_{A} / \dot{Q}$.

The $\dot{\mathrm{V}}_{\mathbf{A}} / \mathbf{Q}$ at the mean of the blood flow distribution averaged 0.78 , and that at the mean of the ventilation distribution 1.03. The points on the $\dot{V}_{\mathrm{A}} / \dot{\mathrm{Q}}$ axis two $\log$ SD above and below the means are, for blood flow, 1.84 and 0.33 , respectively, and for ventilation 2.07 and 0.51 , respectively. Thus, more than $95 \%$ of both ventilation and blood flow are confined between $\dot{\mathrm{V}}_{\mathbf{A}} / \dot{\mathbf{Q}}$ ratios of 0.3 and 2.1, and these limits form a convenient definition of the range of $\dot{V}_{\mathrm{A}} / \dot{\mathrm{Q}}$ in normal young subjects in the semirecumbent position.

In all subjects in this group there was no skewness to the curves so that the distributions were virtually symmetrical along the $\dot{\mathrm{V}}_{\mathrm{A}} / \dot{\mathrm{Q}}$ axis. This was assessed quantitatively by calculating the third moment of the distributions about the mean (again on a log scale). If the third moment is zero, the distribution is perfectly symmetrical; a negative value indicates the presence of a tail (of ventilation or blood flow) in areas of low $\dot{\mathrm{V}}_{\mathrm{A}} / \dot{\mathrm{Q}}$ but not in high $\dot{\mathrm{V}}_{\mathrm{A}} / \dot{\mathrm{Q}}$ areas, and vice versa. The mean third moment of the blood flow distributions was +0.01 , and that for ventilation -0.03 , confirming the virtual lack of skewness. Values for individual subjects are shown in Table II.

It is of interest to compare the dead space calculated by the present method with physiologic dead space computed from the Bohr formula with the arterial and mixed expired $\mathrm{P}_{\mathrm{CO}_{2}}$ values. In both cases, the methods give a value that includes instrumental dead space, anatomic dead space, and ventilation to unperfused alveoli. In addition, the Bohr dead space includes deadspacelike effects of all regions whose alveolar $\mathrm{P}_{\mathrm{CO}_{2}}$ are less than the arterial level. By contrast, the present method only includes the dead-spacelike effect of units with a $\dot{V}_{\mathbf{A}} / \dot{Q}$ over 100 . As a result, when the Bohr dead space is due in part to the presence of high $\dot{\mathrm{V}}_{\mathrm{A}} / \dot{Q}$ areas with $\dot{\mathrm{V}}_{\mathrm{A}} / \dot{\mathrm{Q}}$ less than 100 , the value given by $\mathrm{CO}_{2}$ should exceed that given by the inert gas analysis.

These considerations may be applied to the data from the young subjects. Since there are very few areas with $\dot{\mathrm{V}}_{\mathrm{A}} / \dot{\mathrm{Q}}$ above 2 (mean less than $2 \%$ of the total ventilation), we would expect the results from each method of calculation to be similar. For the young subjects, there is fairly close agreement (Table II). The slope of the regression line is 1.08 , the intercept is -3.2 , and correlation coefficient is 0.76 .

Group II: older subjects aged 39-60 yr. Fig. 2 shows the distribution in one older subject breathing room air (E.L.). Comparison of this figure with that for the young subject (Fig. 1) shows a little more dispersion of both ventilation and blood flow (log SD of blood flow 0.57 , and that for ventilation 0.48 ). The range of $\dot{\mathrm{V}}_{\mathrm{A}} / \dot{\mathrm{Q}}$ is correspondingly greater, namely, from 0.07 to 3.0 , but is still under two decades of $\dot{\mathrm{V}}_{\mathrm{A}} / \dot{\mathrm{Q}} .7 .4 \%$ of the blood flow and $0.3 \%$ of the ventilation lie below the lower limit of normal for young subjects as defined above, while $0.5 \%$ of the blood flow and $1.0 \%$ of the ventilation lie above the upper normal limit given above. Thus, although there is more dispersion in this subject than in the average young subject, there are no areas of very high or very low $\dot{\mathrm{V}}_{\mathbf{A}} / \dot{\mathrm{Q}}$. There was no shunt in this subject. In the older subjects as a group, mean shunt was only $0.08 \%$. 
TABLE II

Summary

\begin{tabular}{|c|c|c|c|c|c|c|c|c|c|c|}
\hline \multirow{3}{*}{$\begin{array}{c}\text { Subject } \\
\text { Conditions studied } \S\end{array}$} & \multicolumn{8}{|c|}{ Group I } & \multirow{2}{*}{\multicolumn{2}{|c|}{$\frac{\text { Group II }}{\text { w. C. }}$}} \\
\hline & \multicolumn{2}{|c|}{ R. D. } & \multicolumn{2}{|c|}{ M. H. } & \multicolumn{2}{|c|}{ M. s. } & \multicolumn{2}{|c|}{ P. B. } & & \\
\hline & Air & $\mathrm{O}_{2}$ & Air & $\mathrm{O}_{2}$ & Air & $\mathrm{O}_{2}$ & $\mathrm{O}_{2}$ & Air & Air & $\mathrm{O}_{2}$ \\
\hline Minute ventilation, liter/min & 7.0 & 8.1 & 6.3 & 7.5 & 9.3 & 11.0 & 8.6 & 8.0 & 7.7 & 9.4 \\
\hline Frequency, min $^{-1}$ & 9.5 & 11.5 & 11 & 11 & 14 & 14 & 15 & 15 & 12 & 20 \\
\hline Tidal volume, $m l$ & 740 & 700 & 570 & 680 & 660 & 790 & 570 & 530 & 640 & 470 \\
\hline Cardiac output, liter/min & 5.8 & 5.8 & 4.9 & 5.2 & 5.8 & 5.6 & 5.4 & 6.3 & 6.0 & 6.3 \\
\hline $\mathrm{PaO}_{2}, \mathrm{~mm} \mathrm{Hg}$ & 91 & 590 & 87 & 600 & 97 & 600 & 600 & 93 & 75 & 506 \\
\hline $\mathrm{PaCO}_{2}, \mathrm{~mm} \mathrm{Hg}$ & 38 & 35 & 41 & 39 & 39 & 35 & 38 & 40 & 38 & 39 \\
\hline $\mathrm{PEO}_{2}, \mathrm{~mm} \mathrm{Hg}_{\mathrm{Hg}}$ & 120 & - & 117 & - & 119 & - & - & 123 & 124 & - \\
\hline $\mathrm{PECO}_{2}, m m \mathrm{Hg}$ & 25 & 23 & 25 & 21 & 24 & 21 & 22 & 22 & 24 & 17 \\
\hline$\dot{\mathrm{V}}_{\mathrm{O}_{2}}, \mathrm{ml} / \mathrm{min}$ & 245 & 260 & 250 & 240 & 340 & 360 & 260 & 250 & 220 & 200 \\
\hline$\dot{\mathrm{V}}_{\mathrm{CO}_{2}}, \mathrm{ml} / \mathrm{min}$ & 200 & 215 & 185 & 180 & 260 & 270 & 215 & 205 & 210 & 190 \\
\hline $\mathrm{AaDo}_{2}, m m \mathrm{Hg}$ & 15 & 83 & 11 & 75 & 2 & 73 & 73 & 9 & 35 & 167 \\
\hline $\mathrm{O}_{2}$ shunt, $\%$ & - & 5.2 & - & 4.4 & - & 3.0 & 4.4 & - & - & 13.5 \\
\hline Shunt, present method, $\%$ & 0 & 0.9 & $\mathbf{0}$ & 0 & 0 & 0.8 & 0.6 & 0 & 0 & 10.7 \\
\hline Bohr deadspace, $\%$ & 41 & 41 & 38 & 48 & 40 & 35 & 45 & 45 & 40 & 57 \\
\hline Deadspace, present method, $\%$ & 38 & 40 & - & - & 43 & 34 & 42 & 44 & 32 & 48 \\
\hline Mean $V_{A} / Q$ blood flow & 0.89 & 0.91 & 0.67 & 1.0 & 0.87 & 1.14 & 0.70 & 0.68 & 0.61 & 0.75 \\
\hline Log SD, blood flow & 0.33 & 0.28 & 0.39 & 0.34 & 0.37 & 0.38 & 0.69 & 0.64 & 1.05 & 0.50 \\
\hline Skew, blood flow & 0 & 0 & -0.01 & 0 & 0 & +0.01 & +0.05 & +0.06 & -2.04 & -0.02 \\
\hline Mean $V_{A} / Q$ ventilation & 1.10 & 1.20 & $-\ddagger$ & - & 1.0 & 1.40 & 1.20 & 1.00 & 1.13 & 0.90 \\
\hline Log SD, ventilation & 0.28 & 0.29 & - & - & 0.33 & 0.32 & 0.49 & 0.40 & 0.76 & 0.33 \\
\hline Skew, ventilation & 0 & 0 & - & - & -0.02 & 0 & -0.10 & -0.07 & +0.11 & 0.0 \\
\hline
\end{tabular}

* All values are means of two measurements made under the same conditions. Because of inaccuracy in the measurement of expired $\mathrm{PO}_{2}$ when breathing $100 \% \mathrm{O}_{2}, \dot{\mathrm{V}}_{2}$ under these conditions is calculated from the measured $\dot{\mathrm{V}}_{\mathrm{CO}_{2}}$ and the respiratory exchange ratio breathing air.

¥ Ventilation data on subject 2 were invalid due to errors in measurement.

$\$$ In each subject, the conditions are shown in chronological order.

There was little skewness in the distributions in this subject (third moments being -0.12 for blood flow and +0.01 for ventilation). Another subject (A.H.), had very similar results (Table II) but it is of interest that in the remaining three in this group (W.C., D.H., and F.M.) there was considerable maldistribution of ventilation and blood flow. The results for subject W.C. are presented in Fig. 3, where it can be seen that $15.5 \%$ of the blood flow and $2.4 \%$ of the ventilation lie below the lower limit of normal in the young group $\left(\mathrm{V}_{\mathrm{A}} / \mathrm{Q}\right.$ of 0.3 ) and that $15.3 \%$ of the ventilation and $3.9 \%$ of the blood flow lie above the upper limit of 2.1. The log $\mathrm{SD}$ of the blood flow distribution is 1.05 and that for ventilation 0.76 . The $\mathrm{V}_{\mathrm{A}} / \mathrm{Q}$ ratio at the mean of the blood flow curve is 0.61 while that for ventilation is 1.13. In addition, the blood flow curve has considerable negative skewness (third moment, - 2.04) due to the areas of $V_{A} / Q$ ratio between 0.01 and 0.1 . However, even in this subject, whose distributions contained the greatest dispersion seen in the entire study, there was no shunt while breathing air.

Another feature in this subject was that his minute ventilation changed between one measurement and the next. In Fig. 3, minute ventilation was $7.7 \mathrm{liter} / \mathrm{min}$, while in a subsequent measurement it had risen to 11.3 liter/min, due to an increase in frequency at the same tidal volume. There was no change in cardiac output. The effect on the resulting $\dot{V}_{\mathbf{A}} / Q$ distribution was only to shift the curves along the $V_{A} / Q$ axis en masse by increasing all values by approximately $50 \%$ toward the direction of higher $V_{A} / Q$. In particular, the shape and dispersion of the distributions was not significantly affected.

Taken as a group, the five older subjects had a mean $\log \mathrm{SD}$ for the blood flow distribution of 0.76 , while that for ventilation was 0.44 . The average $V_{A} / Q$ at the mean of the blood flow distribution was 0.78 , and that for ventilation was 0.92 , while the mean third moment was -0.90 for blood flow and +0.02 for ventilation. Thus in summary, the distributions were broader in the older subjects, both with respect to ventilation and blood flow, and the blood flow curve was skewed due to the presence of areas of low $V_{A} / Q$. The distribution of ventilation was essentially log-normal. Individual results are given in Table II.

The total dead spaces computed by the present method and from the arterial and mixed expired $\mathrm{P}_{\mathrm{CO}_{2}}$ were compared just as for the young subjects. As explained previously, a discrepancy between the two would be expected when regions of high $V_{A} / Q$ are present. Since there was more inequality of ventilation and blood flow in the older subjects, the Bohr dead 


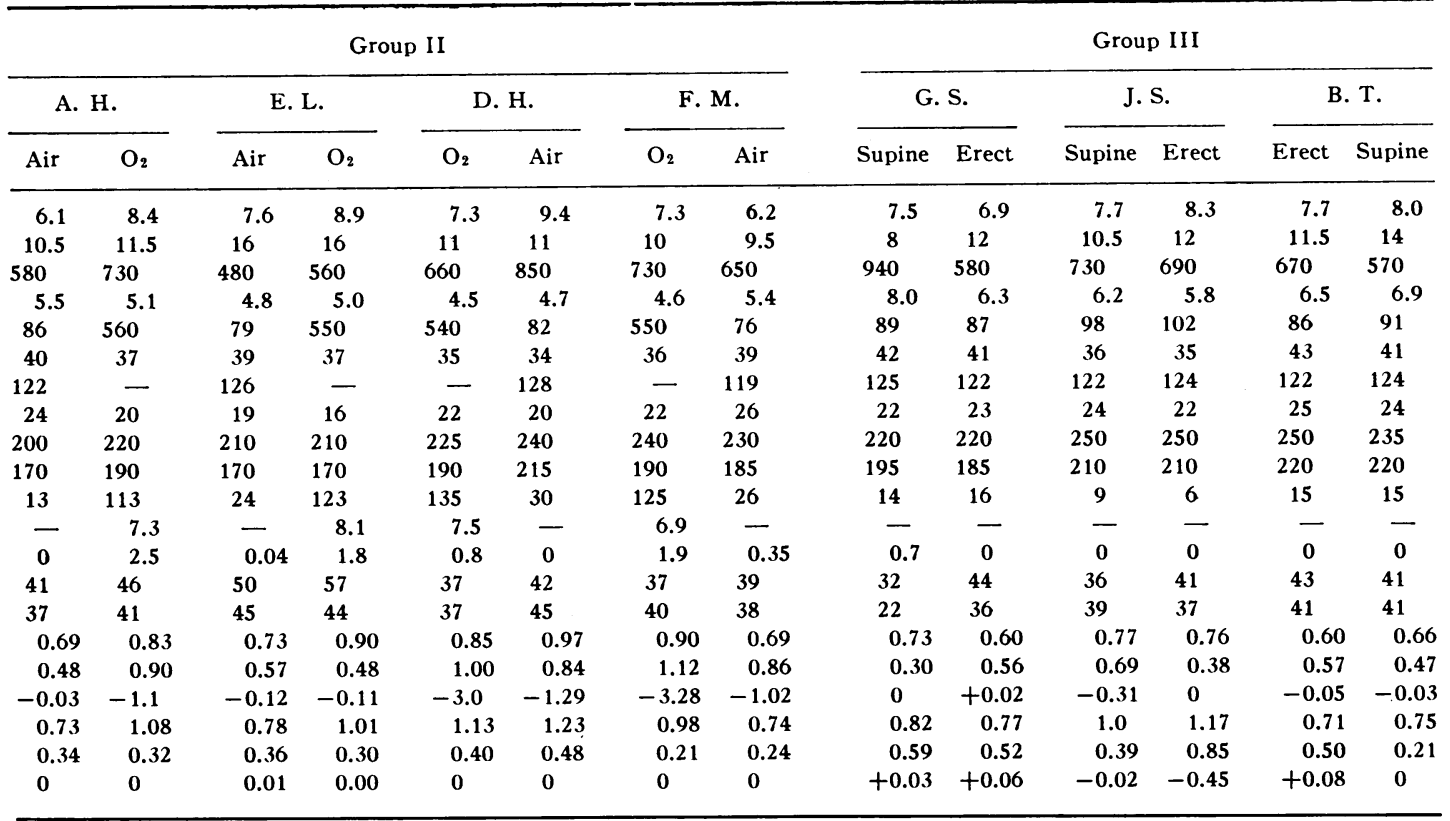

spaces exceeded those measured by the present method in several cases, as expected (Table II). Mean Bohr dead space was $43.8 \%$, while the dead space by the present method was $40.1 \%$, the difference being significant at the 0.05 level.

\section{Distributions in semirecumbent subjects breathing $100 \%$ oxygen}

Group 1: young subjects aged 21-24. Irrespective of the order of the studies (i.e., whether the measurements on oxygen preceded or followed those on room air), two differences were noted between the results during air breathing and those during oxygen breathing.

First, as a consequence of mild hyperventilation while breathing $\mathrm{O}_{2}$, there was a shift in both the ventilation and blood flow curves towards higher $\dot{\mathrm{V}}_{\mathrm{A}} / \dot{\mathrm{Q}}$, by an amount appropriate to the change in the ratio of alveolar ventilation to cardiac output. As a group, the average $\dot{V}_{A} / Q$ ratio at the mean of the blood flow distribution increased from 0.78 to 0.94 and that for ventilation from 1.03 to 1.27 . This was not associated with significant changes in the shape or dispersion of the distributions. The mean $\log \mathrm{SD}$ was 0.43 on air and 0.44 on $\mathrm{O}_{2}$ for blood flow; the values were 0.35 to 0.37 for ventilation. Both distributions remained unskewed.
The change of greater interest, however, was the development of blood flow to unventilated areas (shunt), in spite of the hyperventilation. Three of the four subjects in this group showed this change, resulting in a mean shunt of $0.5 \%(P<0.05)$. These changes occurred within $30 \mathrm{~min}$ of breathing oxygen. It should be pointed out that the subjects were all asked to breathe "normally", and that occasional sighs and deep breaths were observed in all. In the subject (P.B.) in whom the measurements were made with $\mathrm{O}_{2}$ breathing first, the shunt was no longer present subsequently during air breathing, indicating its ready reversibility.

The distributions of blood flow for the subject shown in Fig. 1 are plotted in Fig. 4 (upper panel) to demonstrate these effects of oxygen.

Group II: old subjects aged 39-60. The changes with oxygen breathing in this group were more complex. While the cardiac output fell insignificantly (mean fall of $3 \%$ ), minute ventilation increased by $14 \%$, like the changes in the young subjects. However, the distributions did not simply shift towards areas of higher $\dot{\mathrm{V}}_{\mathrm{A}} / \mathrm{Q}$, since in addition there was an increase in the blood flow to low $V_{A} / Q$ areas and the development of shunts. The result was only a small rise in average $\mathrm{V}_{\mathrm{A}} / \mathrm{Q}$ at the mean (from 0.78 to 0.84 for blood flow and 0.92 to 1.02 for ventilation), since the effect of 


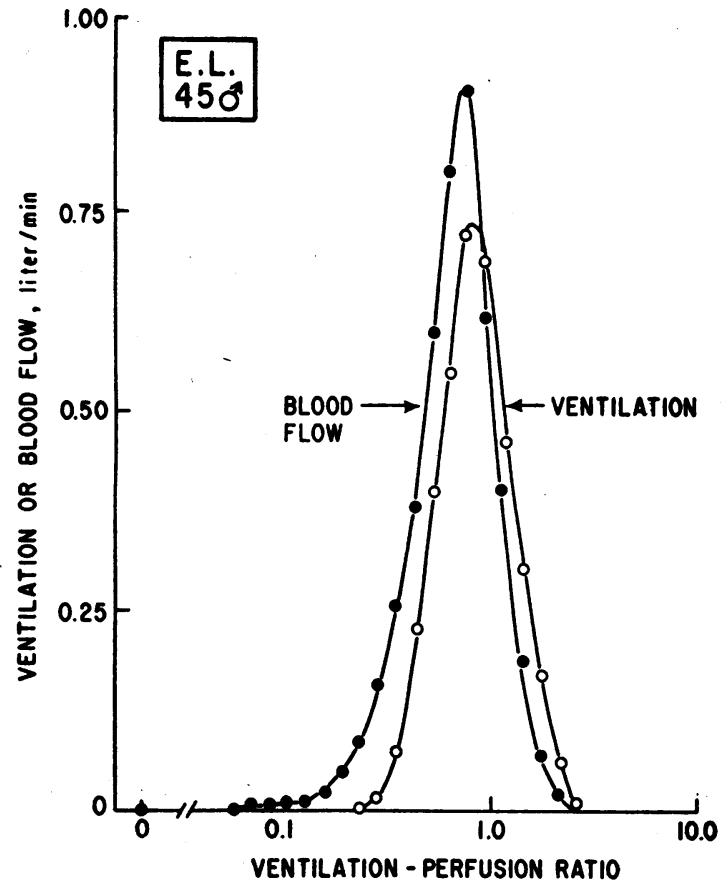

FIGURE 2 The distribution of ventilation and blood flow in an older subject (E. L.) breathing room air. Compared with the young subject (Fig. 1), there is more dispersion in both curves, and a small tail of blood flow in low $\dot{V}_{\mathbf{A}} / \dot{Q}$ areas, so that the blood flow distribution is not log-normal. There is still no shunt, and there are no areas of very high or low $\dot{V}_{\mathbf{A}} / \dot{Q}$.

hyperventilation was partly offset by the increase in low $\dot{\mathrm{V}}_{\mathbf{A}} / \dot{\mathrm{Q}}$ areas. There was little change in the dispersion of the distributions (from $\log \mathrm{SD} 0.76$ to 0.80 for

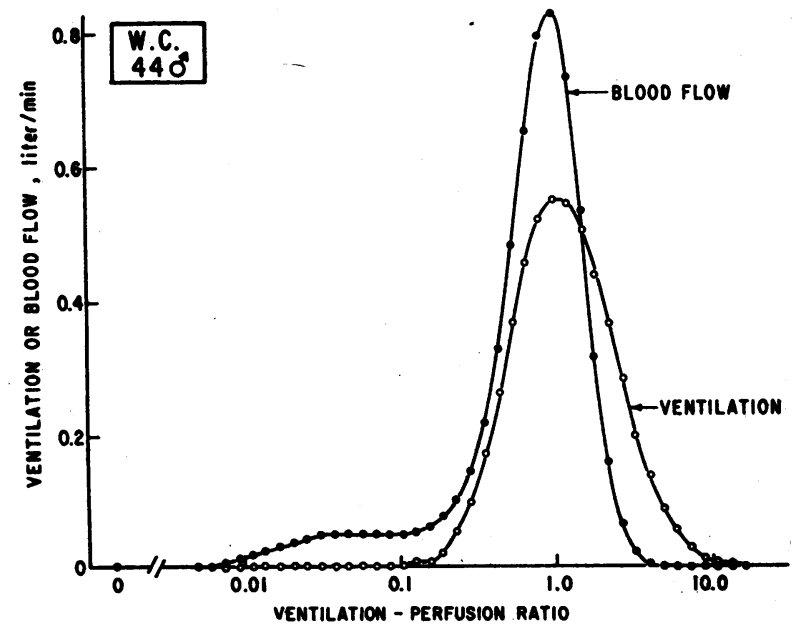

FIGURE 3 The distribution of ventilation and blood flow in subject W. C. breathing room air. As distinct from the subject in Fig. 2, this man demonstrated areas of low $\dot{\mathrm{V}}_{\mathbf{A}} / \dot{Q}$, with units as low as $\mathbf{0 . 0 1}$. However, there was still no shunt, and although the main body of the distributions showed more dispersion than those in Fig. 2, there were no areas with $\dot{\mathrm{V}}_{\mathrm{A}} / \dot{Q}$ greater than 10 . blood flow and 0.44 to 0.31 for ventilation) or in the skewness of ventilation (third moment, 0.02 to 0.00 ) but the blood flow distributions became more negatively skewed (third moment, -0.90 to -1.50 ) due to the increased blood flow in low $\dot{\mathrm{V}}_{\mathbf{A}} / \dot{Q}$ areas.

In all subjects, a shunt appeared (mean value $3.2 \%$ ) after breathing oxygen for $30 \mathrm{~min}$. As for the young subjects, this shunt was present only during oxygen breathing, whether before or after air breathing. In on subject (W.C.), shown in Fig. 4 (lower panel), the shunt reached a value of $10.7 \%$. Note that the main body of the distribution in this case was virtually unaltered while the blood perfusing units in the $\dot{\mathrm{V}}_{\mathbf{A}} / \dot{\mathbf{Q}}$ range $0.005-0.1$ (amounting to $9.6 \%$ of the cardiac output) disappeared. Hypotheses consistent with the
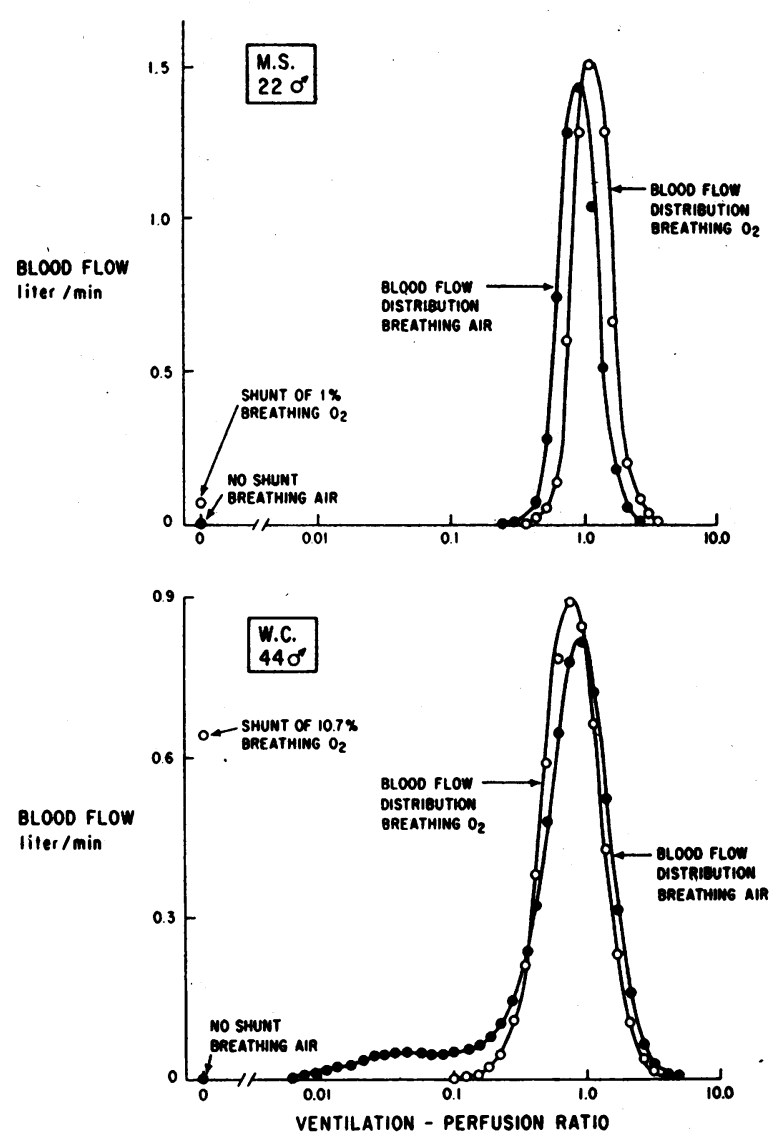

FIGURE 4 Distributions of blood flow breathing both air and $100 \%$ oxygen in one young subject and one older subject. In the young man, (M. S.) there was an overall shift due to hyperventilation, and, a shunt of $1 \%$ appeared. The older subject, (W. C.) demonstrated major changes. The shoulder of blood flow in low $\dot{V}_{A} / \dot{Q}$ areas breathing room air has disappeared on breathing oxygen, while at the same time a shunt of $10.7 \%$ developed. Quantitatively, the amount of blood flow in the low $V_{\mathbf{A}} / \dot{Q}$ regions breathing room air closely matched the degree of shunt on oxygen. The main body of the distribution was unaltered. 
conversion of areas of low $\dot{\mathrm{V}}_{\mathbf{A}} / \dot{\mathrm{Q}}$ into shunt during oxygen breathing are discussed later.

Direct sampling of mixed venous blood was not done in these studies, but since arterial $\mathrm{P}_{\mathrm{O}_{2}}$, oxygen uptake, and cardiac output were measured, the arteriovenous oxygen difference breathing oxygen, and hence the shunt fraction, could be calculated. This " $\mathrm{O}_{2}$ " shunt and that given by the inert gas measurements are shown in Table II. In every case the $\mathrm{O}_{2}$ shunt exceeded the inert gas shunt, but there was an almost constant difference between the two over the range studied. This difference averaged $4.5 \%$ of the cardiac output.

There are two reasons for this consistent discrepancy. First, the venous admixture effect produced by emptying of the bronchial and Thebesian veins into the left side of the circulation is detected as shunt by the oxygen method. This is not the case in the inert gas method, because the inert gas concentrations are virtually unaltered in these circulations. This explanation probably accounts for up to half of the difference between the methods. The remainder of the discrepancy is proabably explained by the errors in measurements of $\mathrm{P}_{\mathrm{O}_{2}}$ when the $\mathrm{P}_{\mathrm{O}_{2}}$ exceeds $400 \mathrm{~mm} \mathrm{Hg}$. Metabolic consumption of oxygen by the blood awaiting analysis and uptake of oxygen by the blood gas electrodes both lead to underestimates of $\mathrm{P}_{\mathrm{O}_{2}}$. That this is the most likely explanation is suggested by the close correlation between the two estimates of shunt when the shunt is larger (of the order of $20 \%$ or more), in experimental dog studies.

Effects of change of posture on the distributions: group III

Fig. 5 shows the distributions in one of the three subjects (J.S.) in this group both supine and erect. Note the increased ventilation and decreased blood flow in areas with $\dot{\mathrm{V}}_{\mathrm{A}} / \dot{\mathrm{Q}}$ ratios above 1 , as the erect posture is assumed. These changes are consistent with the known effects of gravity, which causes underperfusion of the apex of the upright lung and thus increased ventilation to high $\dot{\mathrm{V}}_{\mathrm{A}} / \dot{\mathrm{Q}}$ areas. In addition, in the supine position, there is more blood flow to moderately low $\dot{V}_{A} / \dot{Q}$ regions, caused perhaps by intermittent ventilation in the dependent zones due to a higher closing capacity.

Note that the blood flow distribution in the erect position is narrower than in the supine position. At first sight this might be thought to be paradoxical in view of the greater topographical differences in blood flow when the subject is erect. However, in this posture, blood flow is more closely matched to $\dot{\mathrm{V}}_{\mathbf{A}} / \dot{Q}$ than is ventilation because of the appreciable ventilation to the apex with its very high $\dot{V}_{\mathbf{A}} / \dot{Q}$. As a result, the plot of blood flow against $\dot{\mathrm{V}}_{\mathrm{A}} / \dot{\mathrm{Q}}$ becomes narrower as the topographical differences increase.

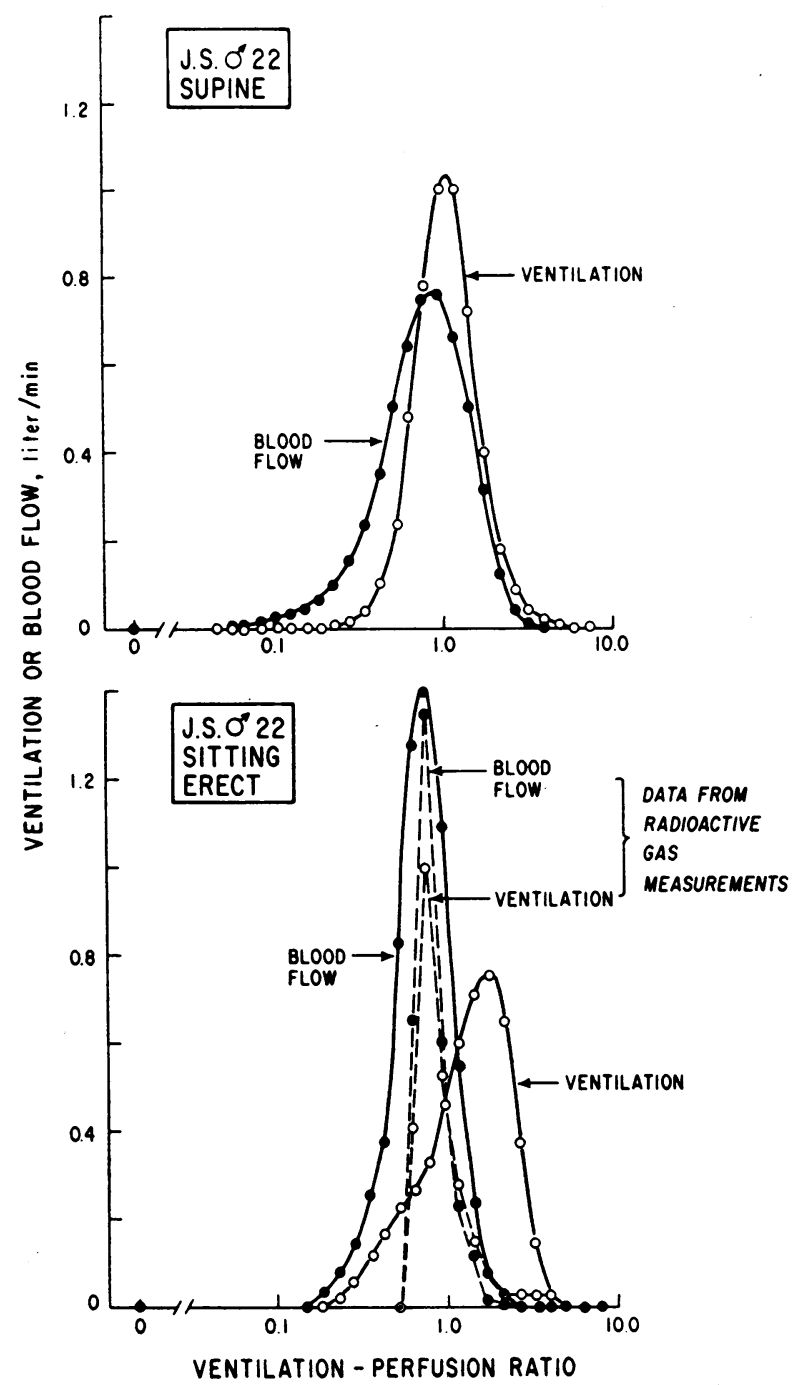

FIGURE 5 Distributions of ventilation and blood flow in subject J. S. determined first supine and then erect. In the erect position there were fewer low, and more high $\dot{\mathrm{V}}_{\mathrm{A}} / \dot{\mathrm{Q}}$ regions. These results are compatible with known differences in topographical distributions of ventilation and blood flow and functional residual capacity, between the two positions. The distributions derived from topographical data in erect subjects are plotted in the lower panel (interrupted lines), showing considerably less dispersion than in the present study.

Also plotted in Fig. 5 are the distributions of ventilation and blood flow derived from the topographical data obtained with radioactive $\mathrm{CO}_{2}$ in upright normal subjects (3). This original data described the blood flow, ventilation, and $\dot{V}_{A} / \dot{Q}$ in nine slices of lung. However, the $\dot{\mathrm{V}}_{\mathrm{A}} / \dot{\mathrm{Q}}$ of these slices are not equally spaced logarithmically, so that a simple plot of blood flow or ventilation versus $\dot{\mathrm{V}}_{\mathrm{A}} / \dot{Q}$ slice by slice is not comparable with the present distributions. This difficulty was overcome by plotting blood flow first and then ventilation cumulatively against $\dot{\mathrm{V}}_{\mathrm{A}} / \dot{\mathrm{Q}}$, and 


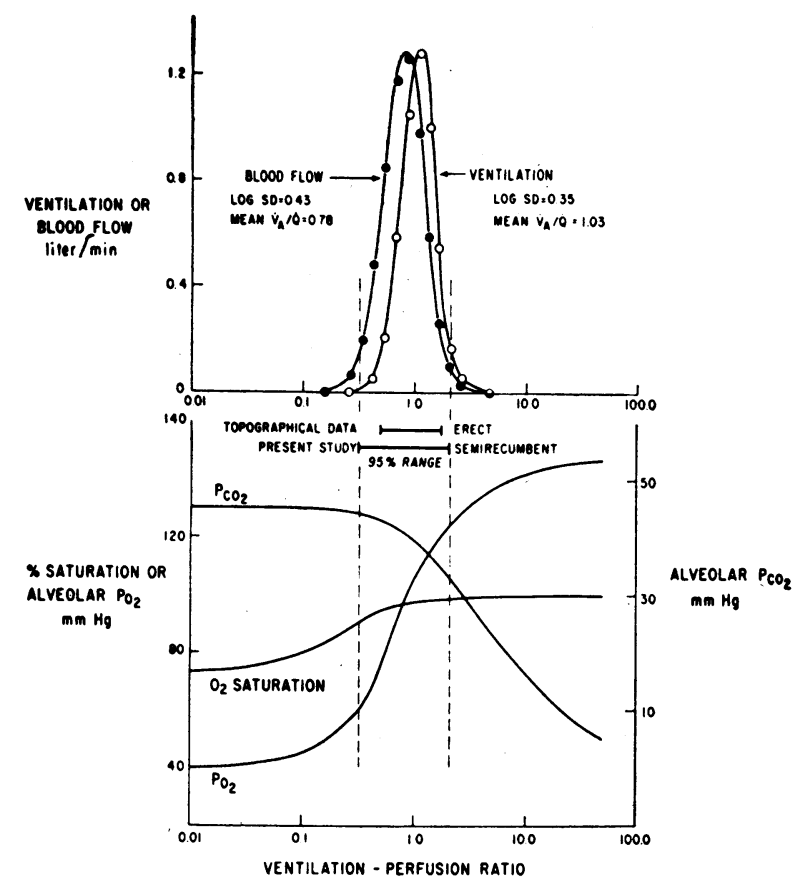

FIGURE 6 The average distribution in young, semirecumbent subjects (upper panel). Lower panel shows alveolar $\mathbf{P}_{\mathrm{O}_{2}}, \mathrm{P}_{\mathrm{CO}_{2}}$, and $\mathrm{O}_{2}$ saturation as a function of $\dot{\mathrm{V}}_{\mathrm{A}} / \dot{Q} .95 \%$ ranges for blood flow and ventilation are shown and indicate a range of alveolar $\mathrm{P}_{\mathrm{O}_{2}}$ of from 60 to 123 and one of $\mathrm{P}_{\mathrm{CO}_{2}}$ from 44 to $43 \mathrm{~mm} \mathrm{Hg}$. Note that the range determined from the present method exceeds that derived from topographical data in erect subjects.

then reading off values at $\dot{V}_{A} / \dot{Q}$ ratios equally logarithmically spaced. In this manner, frequency distributions of ventilation and blood flow were derived and compared in Fig. 5 with the present data.

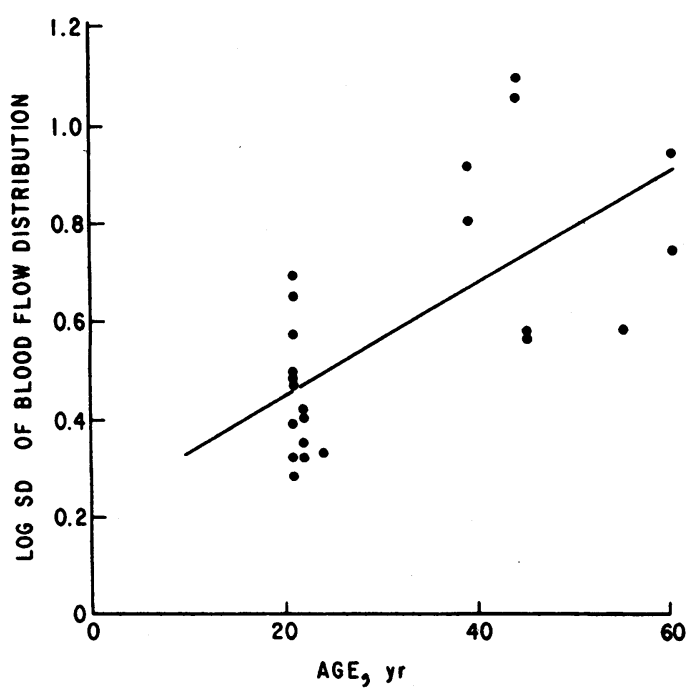

FIGURE 7 Increase in log SD with age. Despite considerable scatter, the dispersion of the distributions increases with age. This is probably responsible for the gradual fall in arterial $\mathrm{P}_{\mathrm{O}_{2}}$ known to occur with age.
There is considerably less dispersion in the distributions derived from the topographical data than in the present case. From Fig. 5 this is seen to be due to less ventilation and blood flow in both high and low $\dot{\mathrm{V}}_{\mathrm{A}} / \dot{\mathrm{Q}}$ units (rather than to a truncation of the curves at only one end). These differences are readily explained by the lack of resolution of the radioactive gas method and its inability to sample to entire lung.

Of the other two subjects in this group, one, (G.S.) showed similar changes with an increase in high $\dot{\mathrm{V}}_{\mathbf{A}} / \dot{\mathrm{Q}}$ areas in the erect position, but the final subject (B.I.) showed only a small difference between the supine and erect positions, with slightly more inequality in the erect position.

\section{Average distributions of ventilation and blood flow in young subjects}

Fig. 6 shows the average distributions of the semirecumbent young subjects (group 1) breathing air. These were calculated from the observed mean log SD and $\dot{V}_{A} / \dot{Q}$ at the mean, independently for both blood flow and ventilation by assuming a logarithmically normal shape. The $95 \%$ limits are drawn, the lower limit being $2 \mathrm{SD}$ below the mean for blood flow $\left(\dot{\mathrm{V}}_{\mathrm{A}} / \dot{\mathrm{Q}}\right.$ of 0.3 ) and the upper $2 \mathrm{SD}$ above the mean for ventilation $\left(\dot{\mathrm{V}}_{\mathrm{A}} / \dot{Q}\right.$ of 2.1$)$. In the lower panel of Fig. 6, alveolar $\mathrm{P}_{\mathrm{O}_{2}}, \mathrm{O}_{2}$ saturation, and alveolar $\mathrm{P}_{\mathrm{CO}_{2}}$ are shown as a function of $\dot{\mathrm{V}}_{\mathrm{A}} / \dot{\mathrm{Q}}$ (mixed venous $\mathrm{P}_{\mathrm{O}_{2}} 40$ and $\mathrm{P}_{\mathrm{CO}_{2}}$ $45 \mathrm{~mm} \mathrm{Hg}$ ). It can be seen that the $95 \%$ range of $\mathrm{P}_{\mathrm{O}_{2}}$ is from 60 to $123 \mathrm{~mm} \mathrm{Hg}$, considerably more than predicted by the topographical distributions (76-120).

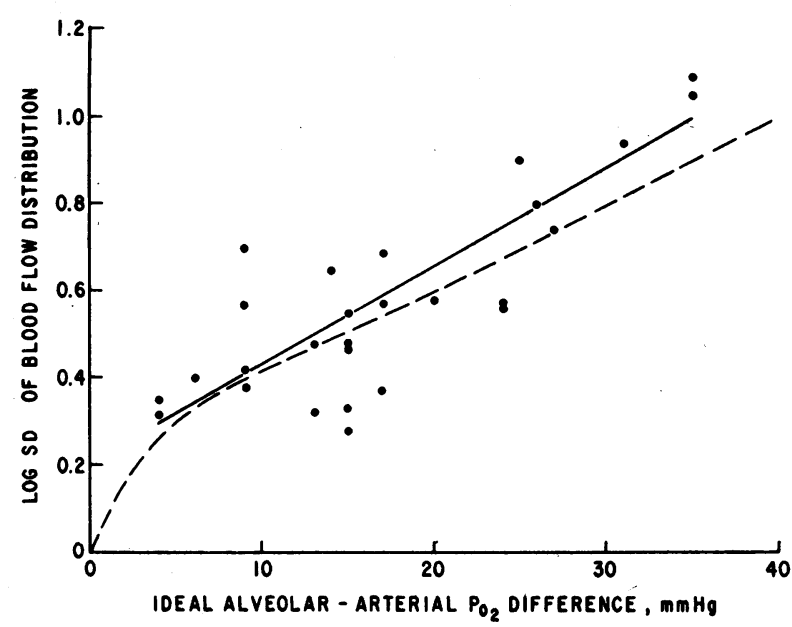

FIGURE 8 Relationship between the alveolar-arterial oxygen difference and $\log \mathrm{SD}$ of blood flow in all subjects breathing room air. There is a good correlation, indicating that the distributions are consistent with independent measurements of oxygen and carbon dioxide exchange. Further, the relationship between these parameters for theoretical log-normal distributions is shown by the interrupted line, and demonstrates a very similar relationship. 
Note that the $95 \%$ range of $\dot{V}_{A} / d$ in the ere ct position according to the topographical Qata is also less than the range indicated in the semirecumbent position for the present study.

\section{Changes in the distributions with age}

Fig. 7 shows the increasing dispersion of the blood flow distributions with age in the nine subjects. There is considerable scatter, so that a precise definition of the relationship between $\log \mathrm{SD}$ and age is not possible, but $\log \mathrm{SD}$ in the older group was significantly higher than in the younger group ( $P$ less than 0.05$)$. On the other hand, there was no clear relationship between age and $\log \mathrm{SD}$ of the ventilation distributions. These findings are explained by the changes with age observed in the measured distributions, namely, the development of regions of low $\dot{V}_{A} / \dot{Q}(<0.1)$ without the appearance of areas of high $\dot{V}_{A} / Q(>10)$ as in Figs. 2 and 3.

\section{DISCUSSION}

Comparison with previous work. There is little previous information concerning distributions of $\dot{\mathrm{V}}_{\mathbf{A}} / \dot{\mathrm{Q}}$ for comparison with the present studies. However, Lenfant and Okubo $(8,9)$ reported distributions measured during nitrogen washout and showed that in their two young normal subjects, the distributions of ventilation and blood flow were very narrow. In addition, they studied three older subjects, who each had broader distributions, as found in this study.

In our studies there are several features consistent with the present limited knowledge of $\dot{\mathrm{V}}_{\mathbf{A}} / \dot{Q}$ distributions. We have pointed out that the position of the distributions in both young and old subjects is appropriate to the ratio of total ventilation to total blood flow, and that the mean of the blood flow curve is always less than that of the ventilation curve. It is reasonable, especially in the young subjects, that there are no areas of very high or very low $\dot{\mathrm{V}}_{\mathbf{A}} / \dot{\mathrm{Q}}$.

It is well known that the arterial $\mathrm{P}_{\mathrm{O}_{2}}$ falls with age in the normal population. Whatever the pathological mechanism, functionally this is most likely to be associated with increasing $\dot{V}_{\mathbf{A}} / \dot{Q}$ inequality. We have shown that the dispersion of the distribution increases with age.

Several indices of oxygen and carbon dioxide exchange were measured in the present studies and may be related to the distributions. For example, the ideal alveolar-to-arterial $\mathrm{P}_{\mathrm{O}_{2}}$ difference increased with the $\log$ SD of blood flow (Fig. 8). In this figure we also show the relationship between the alveolar-arterial difference and $\log \mathrm{SD}$ for theoretical, log-normal distributions. This theoretical relationship is remarkably similar to the measured relationship and it shows an abrupt inflection towards the origin for low values of A-a difference, which were beyond our range of measure- ment. Other indices are the Bohr dead space for $\mathrm{CO}_{2}$ and the dead space measured by the inert gas method. The two values were very similar except when areas of high $\dot{V}_{\mathrm{A}} / \dot{Q}$ were present, when, as previously mentioned, the Bohr dead space for $\mathrm{CO}_{2}$ exceeded that of the inert gas method, because of contributions from units with high $\dot{\mathrm{V}}_{\mathbf{A}} / \dot{\mathrm{Q}}$. A third point of comparison is the shunt measured by the present method and that obtained while breathing $100 \%$ oxygen by standard methods. Although there was a previously explained systematic difference between the two measurements, they ran parallel to one another. Finally, the changes in the distributions with posture were consistent with the known effects of gravity, in that areas of higher $\dot{\mathrm{V}}_{\mathrm{A}} / \dot{\mathrm{Q}}$ appeared as the subjects moved from the supine to the erect positions.

Effects of breathing $100 \%$ oxygen on the distributions. In eight of the nine subjects studied while breathing oxygen, a shunt developed within $30 \mathrm{~min}$ of commencing oxygen breathing. This was true irrespective of the order of the study, implying ready reversibility of the shunt on breathing room air again. The magnitude of the shunt was minimal in subjects with very narrow distributions, and greatest when blood flow was present in low $\dot{\mathrm{V}}_{\mathrm{A}} / \dot{\mathrm{Q}}$ areas (less than 0.1) while breathing room air. In subject W.C., in whom the shunt increased from zero breathing air to $10.7 \%$ breathing oxygen, an approximately equivalent $(9.6 \%$ of blood flow) region of low $\dot{V}_{A} / \dot{Q}$ disappeared without significant change in the main body of the distribution (Fig. 4, lower panel).

Such behavior would be expected to result from atelectasis after denitrogenation as predicted by Briscoe, Cree, Filler, Houssay, and Cournard (18) in 1960. They argued that as the alveolar $\mathrm{P}_{\mathrm{O}_{2}}$ rose in low $\dot{V}_{A} / \dot{Q}$ units from near mixed venous levels to near one atmosphere as the inspired $\mathrm{P}_{\mathrm{O}_{2}}$ was raised, there would be an increase in the flux of oxygen from alveolar gas into capillay blood. It would then be possible for this flux to exceed the rate of delivery of fresh gas into the alveoli, thus resulting in a progressive loss of alveolar volume and eventually in atelectasis. We suggest that a second, synergistic mechanism may act to cause further atelectasis as the alveolar $\mathrm{P}_{\mathrm{O}_{2}}$ rises. This mechanism is the release of hypoxic vasoconstriction, which would result in an increase in the blood flow and hence reduction in $\dot{V}_{A} / \dot{Q}$ in these same units of low $\dot{V}_{A} / \dot{Q}$. As the $\dot{V}_{A} / \dot{Q}$ falls by this mechanism, the likelihood of atelectasis on the basis of the first mechanism increases. Calculations indicate that both these effects will also result in the lowering of the $\dot{\mathrm{V}}_{\mathrm{A}} / \dot{\mathrm{Q}}$ in areas whose initial $\dot{\mathrm{V}}_{\mathbf{A}} / \dot{\mathrm{Q}}$ breathing room air is high enough (about $0.1-0.7$ ) that atelectasis during oxygen breathing does not occur, but whose $\mathrm{PAO}_{2}$ is still fairly low during air breathing. When the $\dot{\mathrm{V}}_{\mathrm{A}} / \dot{\mathrm{Q}}$ ratio exceeds about 0.7 , there is virtually no change 
with oxygen, since the $\mathrm{PAO}_{2}$ breathing air is high enough that there is little change in vasoconstriction or flux of $\mathrm{O}_{2}$ during $\mathrm{O}_{2}$ breathing. Thus in addition to the development of shunt, oxygen breathing would be expected to increase blood flow to low $\dot{\mathrm{V}}_{\mathbf{A}} / \mathbf{Q}$ areas and thus result in a skewing of the blood flow distribution. In the older group of subjects, this was in fact observed, while in the younger subjects very little change was seen because during room-air breathing the distributions contained very little blood flow in low $\dot{\mathrm{V}}_{\mathrm{A}} / \mathbf{Q}$ regions.

Whatever the mechanisms, these results have important clinical implications. If a measurable shunt develops within $30 \mathrm{~min}$ in normal, nonsmoking volunteers breathing oxygen spontaneously, then hypoxic patients, who presumably have more areas with reduced $V_{A} / \dot{Q}$, probably run a greater risk of developing shunt when given oxygen to breathe. This may be especially true after operations where poor lung expansion compounds the issue.

Limitations of the method. The ability of the method to distinguish between shunt and regions of low $\dot{\mathrm{V}}_{\mathbf{A}} / \dot{\mathrm{Q}}$ depends on the low solubility of the least soluble gas $\left(\mathrm{SF}_{6}\right)$ used in the method. In practice, units with $\mathrm{V}_{\mathrm{A}} / \mathrm{Q}$ less than 0.005 cannot be separated from shunt when $\mathrm{SF}_{6}$ is the least soluble gas. If, for example, a gas existed that was 10 times less soluble than $\mathrm{SF}_{6}$, it would be possible to distinguish between shunt and units with $V_{A} / Q$ of 0.0005 .

In a similar manner, the resolution between totally unperfused areas and those with high $\dot{\mathrm{V}}_{\mathrm{A}} / \dot{Q}$ depends on the solubility of the most soluble gas, acetone. With this gas, the method can separate areas whose $\dot{V}_{A} / \dot{Q}$ ratio is 100 from unperfused regions. As a result, the working range of $\dot{\mathrm{V}}_{\mathrm{A}} / \dot{Q}$ is from 0.005 to 100 . Over this range, distributions with up to three separate modes can be accurately described.

When only one mode is present, its position, shape, and dispersion are accurately measured except for the extreme case of a truly homogeneous lung. When the computer program used in the method is fed data corresponding to such a lung, the result is a very narrow distribution centered at the exact $\dot{\mathrm{V}}_{\mathrm{A}} / \dot{\mathrm{Q}}$ of the given homogeneous lung. In other words, when there is zero dispersion in the real lung, the analysis returns a distribution that contains a small amount of dispersion, but which is otherwise accurate. As an indication of the error this will cause, the narrowest distribution that can be accurately recovered is one in which the log $\mathrm{SD}$ of blood flow is $\mathbf{0 . 2 5}$ and the alveolar-to-arterial $\mathrm{P}_{\mathrm{O}_{2}}$ difference is $5 \mathrm{~mm} \mathrm{Hg}$. Even in the present study, in which normal subjects have been studied, this limit, although approached, has not been exceeded.

Repeatability of the distributions. The log SD for both blood flow and ventilation distributions was measured from the first and second measurements separated by 5 min (see Methods). In most cases there was close correspondence, and the correlation coefficient from all points in the table was 0.91 , the slope of the regression line was 0.95 , and its intercept 0.03 . Correspondence was equally good over the entire range of $\log \mathrm{SD}$ measured.

Errors in cardiac ouput, ventilation, and inert gas measurements. The information required for measurement of the distributions consists of cardiac output, minute ventilation, and the concentrations of the six inert gases, in both arterial blood and mixed expired gas.

Errors in the inert gas measurements have been discussed elsewhere in detail (16) and are small. The standard deviation of the measurement of these gases is less than $3 \%$ of the concentration in both gas and blood for all gases except $\mathrm{SF}_{6}$, for which the standard deviation is $5.7 \%$. The effects of such errors on the resulting distributions can be shown to be small.

Errors in the measurement of cardiac output and minute ventilation may be larger, so that it is important to assess the effects of such errors on the results. This was done in the following way. The data for the distributions shown in Figs. 1 and 3 were reprocessed by the computer program with cardiac outputs of $\pm 20 \%$ of the measured value, but with the original inert gas concentrations in arterial blood and expired gas. The resulting distributions were not significantly different from the actual curves in either the shape or dispersion (log SD). The only significant difference was the positioning of the distributions along the $\dot{\mathrm{V}}_{\mathbf{A}} / \dot{Q}$ axis. For a $20 \%$ underestimate in cardiac output, the distributions were shifted to the right (i.e., towards higher $\dot{\mathrm{V}}_{\mathrm{A}} / \dot{\mathrm{Q}}$ by about $20 \%$. For example, if the $\dot{\mathrm{V}}_{\mathbf{A}} / \dot{\mathrm{Q}}$ at the mean of the distribution was 0.8 , an error of this size would increase that mean $\dot{V}_{A} / \dot{Q}$ value to 0.96 . Such a shift is relatively small, compared with the range of $\dot{V}_{\mathbf{A}} / \dot{Q}$ ratios encountered. In the analysis, cardiac output and ventilation are used as ratios of one another, so that a $20 \%$ overestimate in ventilation will produce an identical effect. Errors in the opposite direction will shift the distributions correspondingly in the opposite direction.

Assumptions. A requirement of the method is that a steady state of gas exchange exists. There is considerable evidence for a steady state in the present studies. During the duplicate sampling procedures, end-tidal and mixed expired $\mathrm{P}_{\mathrm{O}_{2}}$ and $\mathrm{P}_{\mathrm{CO}_{2}}$ were montoried continuously and found to be stable. Arterial blood gases were constant to within $3 \mathrm{~mm} \mathrm{Hg}$ over this period, and the duplicate measurements of cardiac output and minute ventilation were very similar. The mean absolute difference between the duplicate cardiac output measurements was $7.7 \%$ and that for venti- 
lation $4.8 \%$. Pulse rate was constant to within 5 beats $/ \mathrm{min}$ in each subject.

The lack of systematic difference between the distributions obtained from the first and duplicate samples is evidence that the six inert gases were also in a steady state of gas exchange. Had a steady state not been in effect due to slow change of gas concentrations in areas of the lung with high volume perfusion ratios but low $V_{A} / Q$, the ratio of arterial to venous concentration would have risen between the initial and duplicate samples, and this was never seen. This would have affected particularly the poorly soluble gases, thereby resulting in an artificially low allocation of blood flow to areas of low $\dot{\mathrm{V}}_{\mathbf{A}} / \dot{\mathrm{Q}}$ in the distributions derived from the initial samples. Finally the fact that the results were physiological and well correlated with independent measurements such as the alveolar to arterial oxygen difference suggests that a steady state had been reached during the infusions.

Another assumption is that for the six test gases, alveolar and end capillary concentrations in any gas exchange unit are identical. This implies complete diffusion equilibration along the capillary, which, as Forster (19) pointed out, is almost certainly the case in the normal lung, since the equilibration time is calculated to be only a few hundredths of a second. Therefore, even if considerable diffusion impairment existed for oxygen and carbon dioxide, it is still likely that diffusion equilibrium would exist for the inert gases. This method would then allow the distribution of $\dot{\mathrm{V}}_{\mathrm{A}} / \dot{\mathrm{Q}}$ to be measured in the presence of diffusion impairment and allow separation of the effects of the two phenomena on gas exchange.

In the present studies, there is evidence that the assumption of inert gas diffusion equilibration is correct. There is also evidence that all of the inequality of ventilation and blood flow is due to differences between units arranged in parallel, and not due to series or stratified inhomogeneity. The basis of both these statements lies in a comparison of the blood flow and ventilation distributions in each subject. Under conditions of diffusion equilibrium and purely parallel $\dot{\mathrm{V}}_{\mathrm{A}} / \dot{Q}$ inequality, the ventilation and blood flow curves could be calculated one from the other, since ventilation is the product of $\dot{\mathrm{V}}_{\mathrm{A}} / \dot{\mathrm{Q}}$ and blood flow in every compartment. If either of the above conditions were not met, then in any gas exchange unit, the alveolar and end capillary concentrations of the inert gas would be different. As a result, the effective $\dot{\mathrm{V}}_{\mathrm{A}} / \dot{\mathrm{Q}}$ of the unit would be different, depending on whether the arterial or the alveolar concentration was being considered, and the computation of ventilation from the product of blood flow and $\dot{\mathrm{V}}_{\mathbf{A}} / \dot{\mathrm{Q}}$ would not be possible. Within the limits of experimental accuracy, ventilation can be calculated from blood flow (this may be seen from Figs.
1,2 , and 3), indicating that incomplete diffusion equilibration or stratified inhomogeneity in normal subjects is not detectable, of if present, has insignificant effects on steady-state gas exchange.

There is additional information concerning rates of diffusion of the inert gases in the lungs. The six gases range in molecular weight from 30 (ethane) to 197.5 (halothane). If diffusion rates were sufficiently slow to produce noticeable effects on gas exchange, halothane should be affected most, In a homogeneous lung, the arterial and alveolar to venous concentration ratios of an inert gas are simple functions of the partition coefficient of the gas and $\dot{V}_{\mathbf{A}} / \dot{Q}$ of the lung. This relationship has been given by several authors $(13,20)$ and is:

$$
\frac{\mathrm{P}_{\mathrm{a}}}{\mathrm{P}_{\overline{\mathrm{v}}}}=\frac{\mathrm{P}_{\mathrm{A}}}{\mathrm{P}_{\overline{\mathrm{v}}}}=\frac{\lambda}{\lambda+\dot{\mathrm{V}}_{\mathrm{A}} / \dot{\mathrm{Q}}}
$$

where $\lambda$ is the blood: gas partition coefficient. It may be seen from this equation that the inverse of both $\mathrm{Pa} / \mathrm{P}_{\overline{\mathrm{v}}}$ and $\mathrm{P}_{\mathbf{A}} / \mathrm{P}_{\overline{\mathbf{v}}}$ are linear functions of the inverse of partition coefficient. This equation is derived assuming that diffusion equilibrium exists. If this relationship is incorrect for halothane because of slow diffusion rates, it will not conform to the straight line predicted from the other gases of much lower molecular weight. In this manner, impaired diffusion of the inert gases may be detected. Even if the lung contains some $\dot{\mathrm{V}}_{\mathrm{A}} / \dot{\mathrm{Q}}$ inequality, the inverse relationship still appears smooth and close to linear so that the same conclusions may be made. In the present studies, this analysis always indicated complete diffusion equilibration.

\section{ACKNOWLEDGMENTS}

We would like to acknowledge with thanks the expert technical assistance of Mr. Peter Naumann, Mr. Richard Gaines, Miss Lee Durand, Mr. George Ozaki, and Miss Nancy Reppeto, and the generous provision of facilities by Dr. Eric Wahrenbrock.

This work was supported by U.S.P.H.S. Grants HL $13867-$ 03, HL 05931 and HL 14169-03 and NASA Grant NGL 05009-109.

\section{REFERENCES}

1. Martin, C. J., F. Cline, Jr., and H. Marshall. 1953. Lobar alveolar gas concentrations: effect of body position. $J$. Clin. Invest. 32 : 617-621.

2. Mattson, S. B., and E. Carlens. 1955. Lobar ventilation and oxygen uptake in man: influence of body position. J. Thorac. Cardiovas. Surg. 30: 676-682.

3. West, J. B., and C. T. Dollery. 1960. Distribution of blood flow and ventilation-perfusion ratio in the lung, measured with radioactive $\mathrm{CO}_{2}$. J. Appl. Physiol. $15: 405-410$.

4. Riley, R. L., and A. Cournand. 1951. Analysis of factors affecting partial pressures of oxygen and carbon dioxide in gas and blood of lungs: theory. J. Appl. Physiol. 4: 77-101.

5. Riley, R. L., A. Cournand, and K. W. Donald. 1951. Analysis of factors affecting partial pressures of oxygen 
and carbon dioxide in gas and blood of lungs: methods J. Appl. Physiol. 4 : 102-120.

6. Briscoe, W. A. 1959. A method for dealing with data concerning uneven ventilation of the lung and its effect on blood gas transfer. J. Appl. Physiol. 14: 291-298.

7. Rochester, D. F., R. A. Brown, Jr., W. A. Wichern, Jr., and H. W. Fritts, Jr. 1967. Comparison of alveolar and arterial concentrations of ${ }^{85} \mathrm{Kr}$ and ${ }^{133} \mathrm{Xe}$ infused intravenously in man. J. Appl. Physiol. 22 : 423-430.

8. Okubo, T., and C. Lenfant. 1968. Distribution function of lung volume and ventilation determined by lung $\mathrm{N}_{2}$ washout. J. Appl. Physiol. 24: 658-667.

9. Lenfant, C., and T. Okubo. 1968. Distribution function of pulmonary blood flow and ventilation-perfusion ratio in man. J. Appl. Physiol. 24: 668-677.

10. Lenfant, C. 1965. Effect of high $\mathrm{FI}_{\mathrm{O}_{2}}$ on measurement of ventilation/perfusion distribution in man at sea level. Ann. N. Y. Acad. Sci. 121: 797-808.

11. Peslin, R., S. Dawson, and J. Mead. 1971. Analysis of multicomponent exponential curves by the Post-Widder's equation. J. Appl. Physiol. 30: 462-472.

12. Wagner, P. D., H. A. Saltzman, and J. B. West. 1974. Measurement of continuous distributions of ventilationperfusion ratios: theory. J. Appl. Physiol. 36: 588-599.
13. Farhi, L. E. 1967. Elimination of inert gas by the lung. Respir. Physiol. 3: 1-20.

14. Klocke, R. A., and L. E. Farhi. 1964. Simple method for determination of perfusion and ventilation-perfusion ratio of the underventilated elements (the slow compartment) of the lung. J. Clin. Invest. 43: 2227-2232.

15. Yokoyama, T., and L. E. Farhi. 1967. Study of ventilation-perfusion ratio distribution in the anesthetized dog by multiple inert gas washout. Respir. Physiol. 3: 166-176.

16. Wagner, P. D., P. F. Naumann, and R. B. Laravuso. Simultaneous measurement of eight foreign gases in blood by gas chromatography. J. Appl. Physiol. 36: 600-605.

17. Hamilton, L. H. 1962. Gas chromatography for respiratory and blood gas analysis. Ann. N. Y. Acad. Sci. 102: 15-28.

18. Briscoe, W. A., E. M. Cree, J. Filler, H. E. J. Houssay, and A. Cournand. 1960. Lung volume, alveolar ventilation and perfusion interrelationships in chronic pulmonary emphysema. J. Appl. Physiol. 15: 785-795.

19. Forster, R. E. 1964. Diffusion of gases. Handb. Physiol. $33: 845$.

20. Kety, S. S. 1951. The theory and applications of the exchange of inert gas at the lungs and tissues. Pharmacol. Rev. 3 : $1-41$. 